\title{
Article \\ The Negative Impact of Night Shifts on Diet in Emergency Healthcare Workers
}

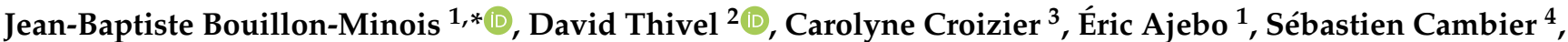 \\ Gil Boudet ${ }^{5}$, Oluwaseun John Adeyemi ${ }^{6}{ }^{(0)}$, Ukadike Chris Ugbolue ${ }^{7}\left({ }^{\circ}\right.$, Reza Bagheri ${ }^{8}{ }^{(}$, Guillaume T. Vallet ${ }^{5} \mathbb{D}^{\circ}$, \\ Jeannot Schmidt ${ }^{1}$, Marion Trousselard ${ }^{9}$ (i) and Frédéric Dutheil ${ }^{10}$ (i)
}

\section{check for}

updates

Citation: Bouillon-Minois, J.-B.

Thivel, D.; Croizier, C.; Ajebo, É.;

Cambier, S.; Boudet, G.;

Adeyemi, O.J.; Ugbolue, U.C.;

Bagheri, R.; Vallet, G.T.; et al.

The Negative Impact of Night

Shifts on Diet in Emergency

Healthcare Workers. Nutrients 2022,

14, 829. https://doi.org/10.3390/

nu14040829

Academic Editor: Michael Wirth

Received: 24 January 2022

Accepted: 14 February 2022

Published: 16 February 2022

Publisher's Note: MDPI stays neutral with regard to jurisdictional claims in published maps and institutional affiliations.

Copyright: (C) 2022 by the authors. Licensee MDPI, Basel, Switzerland. This article is an open access article distributed under the terms and conditions of the Creative Commons Attribution (CC BY) license (https:// creativecommons.org/licenses/by/ $4.0 /)$.
1 Emergency Department, CHU Clermont-Ferrand, Université Clermont Auvergne, CNRS, LaPSCo, Physiological and Psychosocial Stress, F-63000 Clermont-Ferrand, France; eric.ajebo_diko@etu.uca.fr (É.A.); jschmidt@chu-clermontferrand.fr (J.S.)

2 Research Center in Human Nutrition, Laboratory AME2P, Université Clermont Auvergne, F-63120 Aubière, France; david.thivel@uca.fr

3 Hematology Department, CHU Clermont-Ferrand, Université Clermont Auvergne, F-63000 Clermont-Ferrand, France; ccroizier@chu-clermontferrand.fr

4 Clinical Research and Innovation Direction, CHU Clermont-Ferrand, F-63000 Clermont-Ferrand, France; scambier@chu-clermontferrand.fr

5 Department of Psychology, Université Clermont Auvergne, CNRS UMR 6024, LaPSCo, F-63000 Clermont-Ferrand, France; gil.boudet@uca.fr (G.B.); guillaume.vallet@uca.fr (G.T.V.)

6 Ronald O. Perelman Department of Emergency Medicine, NYU School of Medicine, New York University Langone Health, New York, NY 10012, USA; oluwaseun.adeyemi@nyulangone.org

7 School of Health and Life Sciences, Institute for Clinical Exercise \& Health Science, University of the West of Scotland, Glasglow G72 0LH, UK; u.ugbolue@uws.ac.uk

8 Department of Exercise Physiology, University of Isfahan, Isfahan 81746-73441, Iran; will.fivb@yahoo.com

9 French Armed Forces Biomedical Research Institute, IRBA, Neurophysiology of Stress, F-91223 Brétigny-sur-Orge, France; marion.trousselard@gmail.com

10 Occupational and Environmental Medicine, CHU Clermont-Ferrand, Université Clermont Auvergne, CNRS, LaPSCo, Physiological and Psychosocial Stress, WittyFit, F-63000 Clermont-Ferrand, France; fdutheil@chu-clermontferrand.fr

* Correspondence: jbbouillon-minois@chu-clermontferrand.fr

\begin{abstract}
Despite the consequences of night-shift work, the diet of night-shift workers has not been widely studied. To date, there are no studies related to food intake among emergency healthcare workers (HCWs). We performed a prospective observational study to assess the influence of night work on the diet of emergency HCWs. We monitored 24-h food intake during a day shift and the consecutive night, and during night work and the daytime beforehand. We analyzed 184 emergency HCWs' food intakes. Emergency HCWs had 14.7\% lower (-206 kcal) of their 24-h energy intake during night shifts compared to their day-shift colleagues (1606.7 \pm 748.2 vs. $1400.4 \pm 708.3 \mathrm{kcal}$, $p=0.049)$ and a $16.7 \%$ decrease in water consumption $(1451.4 \pm 496.8$ vs. $1208.3 \pm 513.9 \mathrm{~mL} /$ day, $p=0.010$ ). Compared to day shifts, night-shift had $8.7 \%$ lower carbohydrates, $17.6 \%$ proteins, and $18.7 \%$ lipids. During the night shift the proportion of emergency HCWs who did not drink for $4 \mathrm{~h}$, $8 \mathrm{~h}$ and $12 \mathrm{~h}$ increased by $20.5 \%, 17.5 \%$, and $9.1 \%$, respectively. For those who did not eat for $4 \mathrm{~h}, 8 \mathrm{~h}$ and $12 \mathrm{~h}$ increased by $46.8 \%, 27.7 \%$, and $17.7 \%$, respectively. A night shift has a huge negative impact on both the amount and quality of nutrients consumed by emergency healthcare workers.
\end{abstract}

Keywords: nutrients; work; well-being; quality of life; prevention; public health

\section{Introduction}

According to the International Labor Organization, night work is defined as "all work which is performed during a period of not less than seven consecutive hours, including the interval from midnight to 5 a.m." [1]. In 2020 in Europe, 22\% of men and 11\% of women worked on shifts that included night work [2], including healthcare workers (HCWs) [2,3]. 
Night work has many health consequences, from disturbance of the circadian rhythm [4], to obesity and cardiometabolic disorders [5-10]. Interestingly, eating disorders are also associated with those pathologies, potentially enhancing the synergistic effect between night work and eating disorders [11]. Additionally, night-shift workers tend to have more irregular eating habits than their day colleagues [12]. Night work also induces a conflict between socially determined diurnal mealtimes, eating habits, the biological rhythm of hunger, satiety, and metabolism $[13,14]$. Some findings showed that meal timing and meal size have an impact on cognitive performance and subjective sleepiness among night-shift workers. Some programs proposed to avoid large meals during the beginning of a night shift and to opt for a small snack to improve performance during the night [15]. Lastly, eating behavior can be influenced by sociodemographic criteria such as age and gender [16], and by occupational characteristics such as experience [16] and workload $[17,18]$. Although nurses have been widely studied, no conclusion can be made and the existing epidemiological evidence on the relationship between night-shift work of nurses and their dietary habits is inadequate to draw any definite conclusions [19]. Emergency HCWs are a perfect example for studying the impact of night shifts [20]. Indeed, emergency departments (ED) are open $24 \mathrm{~h}$ a day, 365 days a year. Furthermore, emergency HCWs are working under stressful conditions such as overcrowding-lack of beds in hospitals [20], life-threatening emergencies [21], the wait for possible disasters [22] with consequences on biomarkers of stress [23,24]. Furthermore, the availability of food is much less important during the night compared to the day in a hospital. It is rarely fresh but often packaged reheated food with a bad presentation. However, food preparation and presentation appears to influence student consumption of school food and adult perception of school meal quality [25]. Given that emergency HCWs work under the time pressure of urgent care, they must both take care of patients and themselves i.e., finding the time to eat and drink. To the best of our knowledge, there are no studies that assessed the influence of night work on the diet among the population of emergency HCWs, nor in relation to their occupational characteristics.

Therefore, the main objective of our study was to assess the influence of night work on the diet of emergency HCWs. Secondary objectives were to study the impact of sociodemographic, and occupational characteristics on the diet of emergency HCWs.

\section{Materials and Methods}

\subsection{Study Design}

We performed a prospective nationwide observational study in five French hospitals-two university hospitals and three non-university hospitals. The main inclusion criterion was to work as an emergency HCW. Exclusion criteria were refusal to participate and pregnancy. This study is part of the SEEK protocol [20,22]. We obtained the ethical approval from Ethics Committee South-East I (DC-2014-2151) and the protocol was registered on ClinicalTrials. gov as number NCT02401607. Each participant had their food intake monitored twice over 24 consecutive hours: (1) during a day shift (from 8:30 a.m. to 6:30 p.m.) + the night (no work, 6:30 p.m. to 8.30 a.m.), and (2) during a rest day (from 8:30 a.m. to 6:30 p.m.) and a night shift (6:30 p.m. to 8:30 a.m.) (Figure 1). Participants also had to complete a questionnaire on their sociodemographic characteristics. 


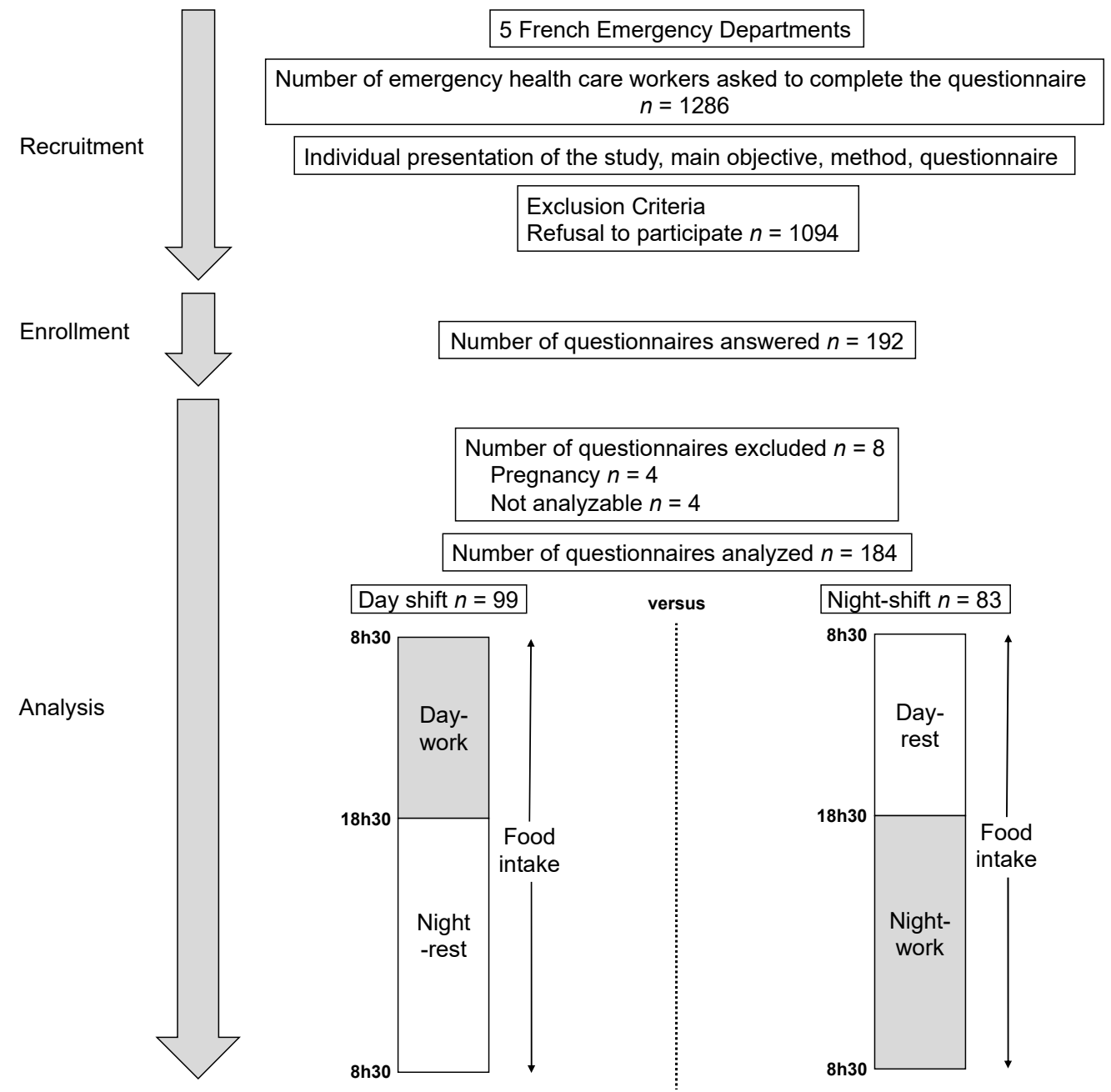

Figure 1. Study design. Among five French emergency departments we were able to recruit 192 emergency health care workers. Eight were excluded because of pregnancy or no data completion. Food intake was studied for 99 emergency health care workers during a day shift and 83 during a night shift.

\subsection{Outcomes}

Participants were asked to complete a 24-h dietary recall that was explained to them by a member of the investigation team. The participants were asked to indicate as precisely as possible all the details regarding the food ingested at each meal and in-between meals. The diaries were reviewed afterward with the participants during a dedicated interview. We next used Nutrilog ${ }^{\circledR}$ (version 3.2, Nutrilog, Marans, France), a diet and nutrition software for health care professionals, to translate participants' answers on nutrients intake using nutrition table Ciqual ${ }^{\circledR}$ on this software [26]. We retrieved total energy intake (kcal), glucids (grammes and \% energy intake, and sugar), lipids (grammes and \% energy intake, and simple, mono- and poly-unsaturated fatty acids), protids (grammes and \% energy intake), calcium, cholesterol, fibres, and water. We further looked at time of intake and more specifically we calculated number of emergency HCWs that did not eat or drink for more than 4,8 , and 12 consecutive hours.

Participants had also to complete a short questionnaire to retrieve their sociodemographic (age, gender, marital status) and work characteristics (occupation, job seniority, and setting-university hospital or not).

\subsection{Statistics}

The main judgment criterion was food intake as quantitative variables. From personal experience and observation in a preliminary non-published study among 10 emergency 
HCWs, there is at least a $20 \pm 20 \%$ decrease in food intake during a night shift compared to a day shift, because of the increased working demands during a night shift due to fewer staff. Using this difference as the main outcome, we calculated that a sample size of 10 participants allowed a statistical power greater than $80 \%$ with an alpha level less than $5 \%$.

Statistical procedures were performed with Stata software (v17, College Station, TX, USA). Quantitative variables were expressed as mean \pm standard deviation (SD), and qualitative variables were expressed as number (\%). The Gaussian distribution for each food intake variable was assessed by a Shapiro-Wilk test. Mean levels of each $24 \mathrm{~h}$ food intake variable were compared between night and day shifts using Wilcoxon (signed rank) tests. Association between food intake, sociodemographic (age, gender, marital status) and work characteristics (occupation, job seniority, and setting-university hospital or not), were assessed using Chi2 for categorical variables, and Spearman correlations for quantitative variables. The influence of shift condition, sociodemographic and work characteristics with each food intake variable were further assessed using univariate regressions-linear regressions for quantitative variables (coefficient and 95 confidence intervals-95\% CI) and logistic regression for qualitative variables (odds ratio and 95\% CI). Significance was set at the $p<0.05$ level.

\section{Results}

We included 192 emergency HCWs from five hospitals. Four emergency HCWs were excluded because pregnancy and four for incomplete data. In total, we analyzed 184 emergency HCWs (Figure 1). Table 1 presents sociodemographic characteristics of the participants.

Table 1. Sociodemographic characteristics. SD = standard deviation, $\mathrm{n}=$ number of participants, $\mathrm{cm}=$ centimeters, $\mathrm{kg}=$ kilograms, $\mathrm{kg} / \mathrm{m}^{2}=$ kilogram per square meter.

\begin{tabular}{cccc}
\hline & All & Male & Female \\
\hline & $\boldsymbol{n}=\mathbf{1 8 4}$ & $\boldsymbol{n}=\mathbf{8 1}$ & $\boldsymbol{n}=\mathbf{1 0 3}$ \\
\hline Age, years & $37.2 \pm 10.2$ & $37.8 \pm 10.4$ & $36.8 \pm 10.1$ \\
Body Mass Index, $\mathrm{kg} / \mathrm{m}^{2}$ & $23.2 \pm 3.9$ & $24.3 \pm 3.8$ & $22.3 \pm 3.7$ \\
Family situation & & & \\
Married/in couple & $127(69 \%)$ & $57(71.3 \%)$ & $70(68.0 \%)$ \\
Single & $56(30.4 \%)$ & $23(28.7 \%)$ & $33(32.0 \%)$ \\
Missing data & $1(0.6 \%)$ & $1(1.2 \%)$ & - \\
Children & & & $46(44.7 \%)$ \\
No children & $86(46.7 \%)$ & $40(49.4 \%)$ & $36(34.8 \%)$ \\
Z1 children & $63(42.3 \%)$ & $27(33.3 \%)$ & $21(20.4 \%)$ \\
Missing data & $34(18.4 \%)$ & $14(17.3 \%)$ & $10.6 \pm 10.4$ \\
Seniority, years & $10.5 \pm 10$ & $10.5 \pm 9.6$ & $10.6 \pm 10.3$ \\
As a provider & $9.9 \pm 9.8$ & $9.0 \pm 9.0$ & $6.9 \pm 8.3$ \\
In the hospital & $6.4 \pm 10$ & $5.6 \pm 6.5$ & \\
In the emergency & & & \\
department & & & \\
\hline
\end{tabular}

\subsection{Main Objective: Impact of Night Shift on Alimentation}

\subsubsection{Quantitative Data}

The night shift group of emergency HCWs reported a $14.7 \%(-206 \mathrm{kcal})$ lower $24-\mathrm{h}$ energy intake compared to the day shift group (1606.7 \pm 748.2 vs. $1400.4 \pm 708.3 \mathrm{kcal}$, $p=0.049$ ). Compared to day shifts, there were a $8.7 \%$ decrease among the night shift group of carbohydrates $(178.8 \pm 81.5$ vs. $163.3 \pm 86.0 \mathrm{~g} / \mathrm{day}, p=0.120), 17.6 \%$ of proteins $(80.6 \pm 30.3$ vs. $66.4 \pm 36.4 \mathrm{~g} /$ day, $p<0.001), 18.7 \%$ of lipids $(75.1 \pm 35.9$ vs. $61.13 \pm 32.7 \mathrm{~g} /$ day, $p=0.030), 18.2 \%$ of simple fatty acids ( $31.8 \pm 16.1$ vs. $26.0 \pm 13.4 \mathrm{~g} /$ day, $p=0.056), 19.1 \%$ of monounsaturated fatty acids $(25.6 \pm 14.2$ vs. $20.7 \pm 14.2 \mathrm{~g} /$ day, $p=0.049), 20.9 \%$ of polyunsaturated fatty acids ( $7.7 \pm 4.8$ vs. $6.13 \pm 4.5 \mathrm{~g} /$ day, $p=0.050)$, 
$13.9 \%$ of calcium $(665.6 \pm 249.3$ vs. $573.3 \pm 297.9 \mathrm{mg} /$ day, $p=0.049), 12.5 \%$ of cholesterol $(318.7 \pm 238.9$ vs. $278.7 \pm 243.0 \mathrm{mg} /$ day, $p=0.161), 11.7 \%$ of fiber $(15.8 \pm 7.1$ vs. $13.9 \pm 8.2 \mathrm{~g} /$ day, $p=0.171)$ and $16.7 \%$ of water consumption (1451.4 $\pm 496.8 \mathrm{vs}$. $1208.3 \pm 513.9 \mathrm{~mL} /$ day, $p=0.010$ ). (Table 2 and Figure 2 ).

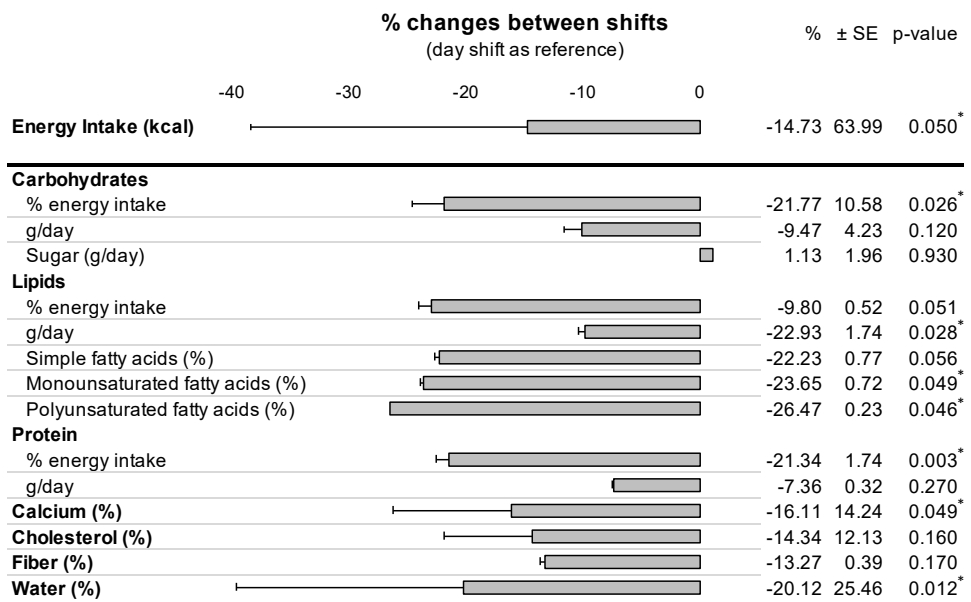

Figure 2. Food intake variations between night and day shifts. Differences in total energy intake, carbohydrates, lipids, protein, calcium, cholesterol, fiber, and water consumptions between day and night shifts among 184 questionnaires. Differences expressed in percentage with day shift as reference. Results: a night shift induces a decrease of all components related to daily ingesta except on sugar. $\mathrm{SE}$ standard error; $p$-value with * are significant (if $<0.05$ ).

Table 2. Impact of night shift on energy intake and water consumption among emergency health care workers. Kcal = kilocalories, $\mathrm{g}=$ gram, $\mathrm{mg}=$ milligrams, $\mathrm{mL}=$ milliliter, $p$-value with * are significant (if <0.05).

\begin{tabular}{ccccc}
\hline & All & Day-Shift & Night-Shift & $\begin{array}{c}\text { Comparisons } \\
\text { between } \\
\text { Shifts }\end{array}$ \\
& & & & $\boldsymbol{p}$-Value \\
\hline Energy Intake (kcal) & $1523.1 \pm 737.0$ & $1606.7 \pm 748.2$ & $1400.4 \pm 708.3$ & $0.049 *$ \\
Carbohydrates (g/day) & $172.1 \pm 83.5$ & $178.8 \pm 81.5$ & $163.3 \pm 86.0$ & 0.120 \\
Lipids (g/day) & $69.1 \pm 35.1$ & $75.1 \pm 35.9$ & $61.13 \pm 32.7$ & $0.030^{*}$ \\
Simple fatty acid & $29.3 \pm 15.4$ & $31.8 \pm 16.1$ & $26.0 \pm 13.4$ & 0.056 \\
Monounsaturated fatty acid & $23.4 \pm 14.4$ & $25.6 \pm 14.2$ & $20.7 \pm 14.2$ & $0.049 *$ \\
Polyunsaturated fatty acid & $7.0 \pm 4.7$ & $7.7 \pm 4.8$ & $6.13 \pm 4.5$ & $0.050^{*}$ \\
Protein (g/day) & $74.5 \pm 33.7$ & $80.6 \pm 30.3$ & $66.4 \pm 36.4$ & $<0.001$ * \\
Cholesterol (mg/day) & $301.3 \pm 240.5$ & $318.7 \pm 238.9$ & $278.7 \pm 243.0$ & 0.161 \\
Fiber (g/day) & $15.0 \pm 7.6$ & $15.8 \pm 7.1$ & $13.9 \pm 8.2$ & 0.171 \\
Calcium (mg/day) & $625.5 \pm 274.2$ & $665.6 \pm 249.3$ & $573.3 \pm 297.9$ & $0.049 *$ \\
Water (mL/day) & $1345.8 \pm 516.6$ & $1451.4 \pm 496.8$ & $1208.3 \pm 513.9$ & $0.010 *$ \\
\hline
\end{tabular}

\subsubsection{Qualitative Data}

Overall during shifts, there were $38 \%$ of emergency HCWs who did not drink for $4 \mathrm{~h}$, $19 \%$ for $8 \mathrm{~h}$, and $5 \%$ for $12 \mathrm{~h}$; and $46 \%$ who did not eat for $4 \mathrm{~h}, 27 \%$ for $8 \mathrm{~h}$, and $9 \%$ for $12 \mathrm{~h}$. More specifically, the night shift group of emergency HCWs reports a proportion of participants who did not drink for $4 \mathrm{~h}, 8 \mathrm{~h}$ and $12 \mathrm{~h}$ increased by $20.5 \%$ (50.0\% vs. $29.5 \%, p=0.015), 17.5 \%(29.3 \%$ vs. $11.5 \%, p=0.009)$, and $9.1 \%(10.3 \%$ vs. $1.3 \%, p=0.018)$ respectively. Similarly, the proportion of emergency HCWs who did not eat for $4 \mathrm{~h}, 8 \mathrm{~h}$ and $12 \mathrm{~h}$ was higher in the night shift group by $46.8 \%$ (72.4\% vs. $25.6 \%, p<0.001), 27.7 \%(43.1 \%$ vs. $15.4 \%, p<0.001)$, and $17.7 \%(19.0 \%$ vs. $1.3 \%, p<0.001)$ (Table 2 and Figure 3$)$ respectively. 


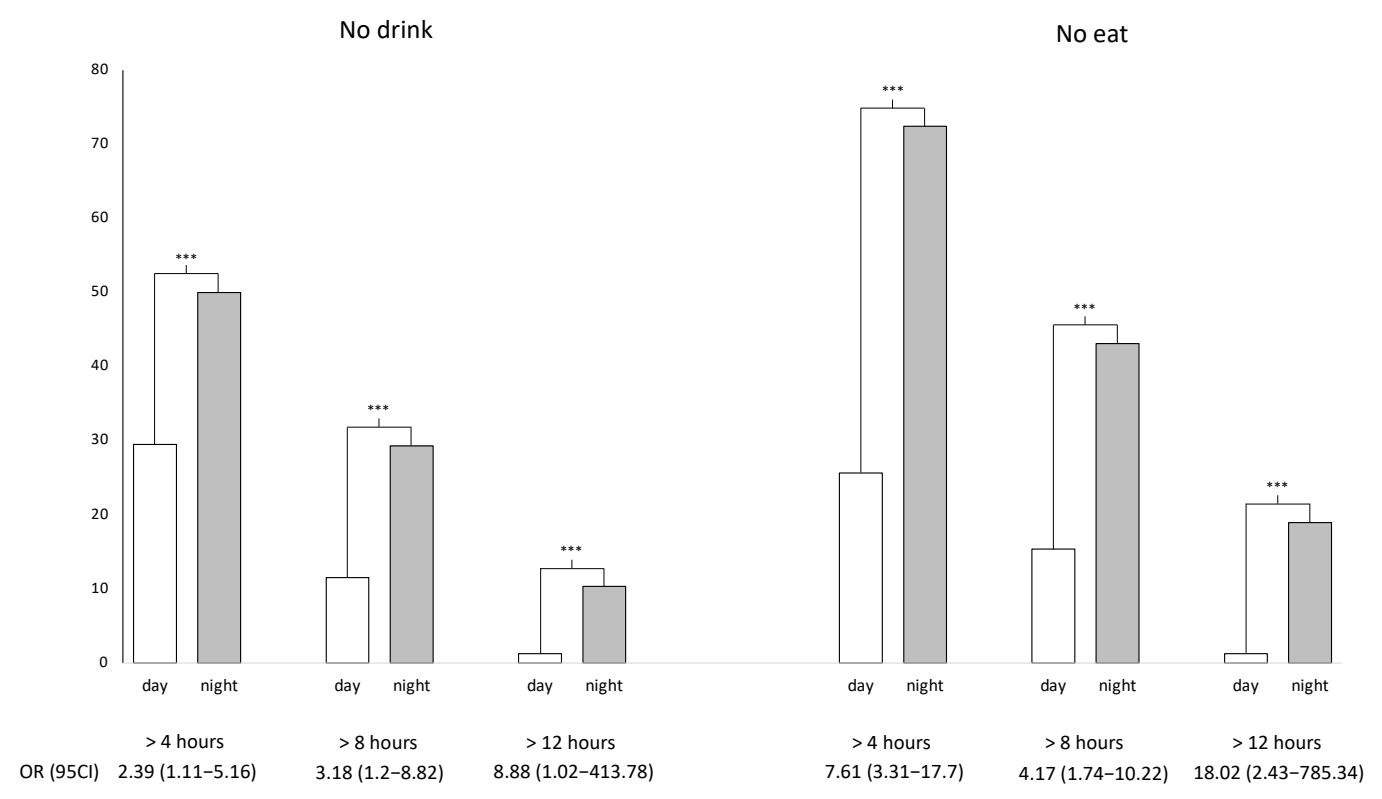

Figure 3. Risk of no-intakes for emergency health care workers during shifts. Percentage of participants declaring not drinking/not eating, over 4-, 8-, or 12-h during night- and day-shifts. A total of 136 questionnaires were analyzed. Odds ratio (OR) was used to access the impact of nightshifts using day-shifts as reference. $95 \% \mathrm{CI}=95 \%$ confidence intervals; ${ }^{* * *}$ represent $p$-value which are all $<0.018$ (significant if <0.05).

\subsection{Regression Analysis}

\subsubsection{Quantitative Variables}

Energy intake is significantly lower among females compared to males (coefficient $=340.1$, $95 \%$ CI 107.5 to $572.7, p=0.004$ ) and among non-university hospitals compared to university hospitals $(378.5,143.9$ to $613.1, p=0.002)$. Consumption of lipids was decreased by night work $(-3.34,-6.59$ to $-0.09, p=0.04)$, and increased by age $(0.19,0.04$ to $0.35, p=0.02)$, and in workers who were single $(3.80,0.36$ to $7.24, p=0.03)$. Simple fatty acid consumption was decreased by night work $(-5.22,-10.34$ to $0.1, p=0.051)$, and increased with age $(0.27,0.02$ to $0.52, p=0.023)$. Cholesterol consumption increased with age $(4.78,1.21$ to $8.34, p=0.009)$, male $(75.8,1.71$ to $149.8, p=0.04)$, and seniority $(5.03,0.27$ to $9.80, p=0.038)$. Night work did not statistically influence other nutrition variables (Figure 4 and Appendix A). 


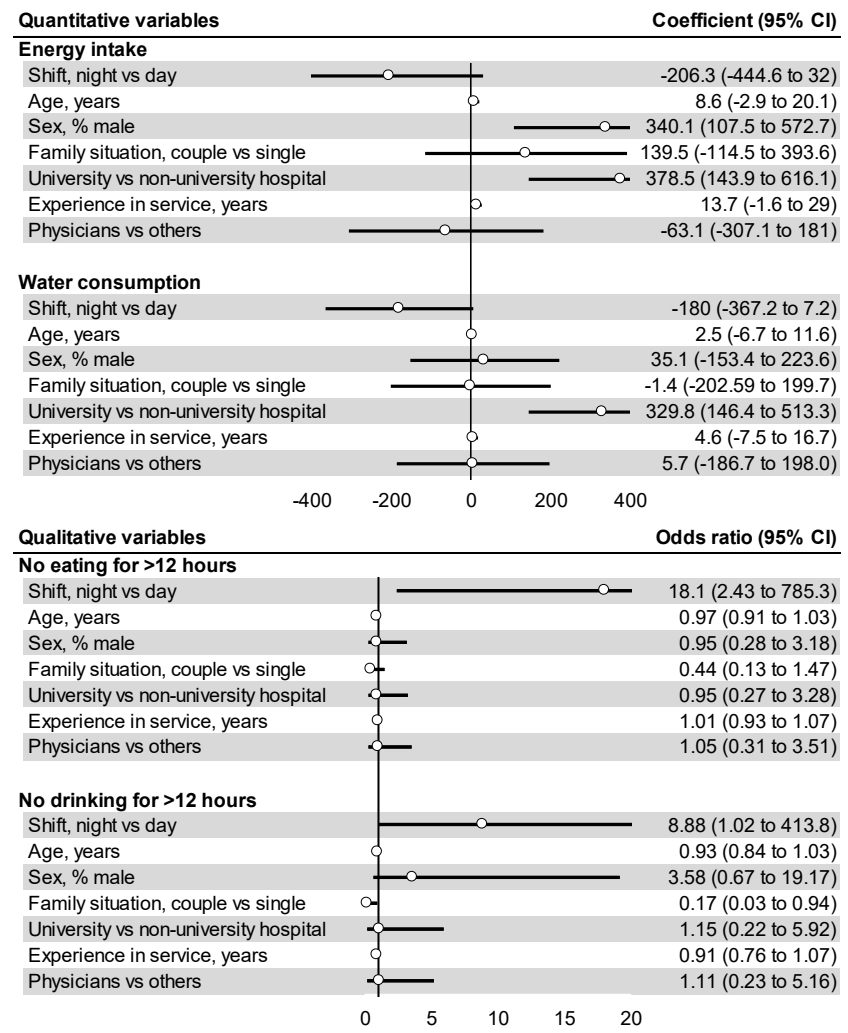

Figure 4. Univariate analysis that found a strong tendency on the impact of night shifts on energy intake, water consumption. Coefficient up to 0 induce a positive impact of the variable (right side of the reference line). Negative coefficient induce a negative impact of the variable (left side of the reference line); $95 \% \mathrm{CI}$ : 95\% confidence interval.

\subsubsection{Qualitative Variables}

Night shifts triggered a rise in the risk of not drinking for more than $4 \mathrm{~h}, 8 \mathrm{~h}$ and $12 \mathrm{~h}$ by $2.4(\mathrm{OR}=2.39,95 \% \mathrm{CI} 1.11$ to $5.16, p=0.015), 3.2(3.18,1.20$ to $8.82, p=0.009)$ and $8.9(8.88,1.04$ to $413.8, p=0.018)$ respectively compared to day shifts. Furthermore, night shifts increased the risk of not eating for more than $4 \mathrm{~h}, 8 \mathrm{~h}$ and $12 \mathrm{~h}$ by $7.6(7.61,3.31$ to $17.7, p<0.001), 4.2(4.17,1.74$ to $10.22, p<0.001)$ and $18(18.0,2.43$ to $785.3, p<0.001)$, respectively, (Figures 3 and 4, and Appendix A). Except for night shift, the regression analysis did not find any impact on sociodemographic, location of work or seniority.

\section{Discussion}

We demonstrated that nightshift has a negative impact on both the amount and quality of nutrients intake among emergency HCWs. Furthermore, 27\% of emergency HCWs do not have time to eat during more than 8 consecutive hours of the night shifts, and they do not even have time to drink for nearly one fifth of them. Main other influencing variables were seniority and location of centers.

\subsection{The Negative Impact of Night Shift on Food Intake}

Emergency HCWs working during a night shift have a slighter 24-h energy intake compared to those working during a day shift, but also compared to daily recommended diet [27]. Literature is not consistent about these results. Although we did not find any study about the impact of night shifts among emergency physicians, there is some among nurses with controversial results. Some found a lower energy intake among night workers versus day workers [28,29] while others did not find any significant differences [30-32]; however, another study found higher food intake among night workers versus day workers [33]. Although we do not study the energy intake the day after the shift, it seems that this low 
food intake is compensated for on the day of recovery after work [29]. We can explain this low food intake in our study. First, emergency HCWs are subjected to daily stress due to overcrowding of EDs [34], lack of beds available in the hospital, and life-threatening emergencies $[35,36]$. However, the impact of stress on eating is controversial. Indeed, while acute stress is able to induce dietary restriction, chronic stress will induce food intake signal thus providing a better response to future stressful events [37]. Many pathophysiological pathways have been studied, especially the impact of ghrelin and leptin as biomarkers of acute stress [38-40]. It would be interesting to study those biomarkers among emergency HCWs. Secondly, sleep restriction and disturbed nychthemeral rhythm promote increased energy intake $[19,41]$.

\subsection{The Amount and Quality of Nutrient Intake and Shifts}

The quality and choice of food during the night shift differs from the day shift [19]. This could induce restrictive behavior. Our results are in accordance with this. Indeed, emergency HCWs eat fewer carbohydrates and lipids during night shifts than their daytime colleagues [28,42]. Those results are also in agreement with the literature. Furthermore, it seems that the main carbohydrate intake during night shifts include the excessive consumption of sweets and sugary drinks [43-45]. Concerning lipids, night workers, and especially permanent night-shift workers, are at risk of dyslipidemia [9]. However, in our study, emergency HCWs eat less lipid and fat during night shifts than during day shifts. This is in line with literature $[28,29,43]$. Another possible explanation is the lack of time to eat during both day and night shifts. It seems that this lack of time leads to an increase in consumption of cold foods and fast foods [31,44,45], which predisposes individuals to obesity and cardiovascular disorders [46,47]. We also showed a low protein consumption during night shifts-type of position held, overwork and the quality of sleep are risk factors for low protein consumption [27,47]. Our results showed a low consumption of water consumed by emergency HCWs. Some of them do not even consume fluids during the entire night shift, i.e., during more than $12 \mathrm{~h}[28,48]$. It seems that coffee/tea and sugary drinks are the preferred drinks mostly consumed during night work [28,33,49].

\subsection{Other Influencing Variables}

We showed a link between age, emergency HCWs' position held and the consumption of lipids, fat, and cholesterol. The more experience they have, the more lipids, fat, and cholesterol they consume. This is in line with a study that shows that eating behavior is influenced by seniority, and age [50]. It seems that experienced workers, with staggered schedules, eat more during the night, but mainly snacks rich in sugar, fat, and energy [50,51]. We also found that males have a higher energy, cholesterol, and protein intake, but also are less able to spend more than $4 \mathrm{~h}$ without eating. This finding is not in agreement with the literature. Indeed, night work induces an increase in the consumption of sugary and fatty foods, possibly in response to stress among emotional eaters, who are most often women $[52,53]$. University hospitals are larger than non-university hospitals, so we could imagine that emergency HCWs have less time to eat because ED is more overcrowded. However, we found that working in a large health center would have a positive influence on the diet of emergency HCWs. According to the literature, night workers in large hospital centers tend to consume more "junk food", which is easily accessible and more convenient to eat [28]. Our study is the first to examine the influence of night work on the diet of emergency physicians. Indeed, the subject often explored nurses or even more often industries in Asia with a population having a very high energy expenditure and a very low socio-economic level. Most of these studies have a low level of evidence (nonrepresentative samples, unsystematic literature reviews) and are difficult to transpose in our population due to very different eating habits and high standards of living [19]. Another potential variable could be the sleep that we did not study the impact of. Indeed, previous literature suggests that night-shift workers obtain less sleep compared to day-shift workers. 
Thus, if night-shift workers have a longer duration awake, they will be hungrier, and so more intake [54].

\subsection{Limitations}

Our study has some limitations. Firstly, the analyses of the dietary data were not necessarily done in the same subjects for day and night as we had more day shifts and fewer night shifts. Secondly, we worked on questionnaires that utilized self-reported information that may have contained some imprecision in the description of the food portions consumed as well as over- or under-declarations on the part of the participants completing the questionnaires. Although our data were collected via a self-assessment questionnaire with self-reported responses, the general methodological quality of our study was good and the risk of bias across participants was reduced through the use of a validated scale presented to every emergency HCW before the beginning of the data collection session. Another limitation is that we did not study the impact of cognition. Indeed, the impact on memory in case of a decrease of attentiveness or responsiveness could impact negatively the ability to fill in the questionnaire. By and large, while quality assurance protocols were put in place for the data collection process, it was difficult to micro-manage the different centers. Lastly, strict inclusion criteria were applied in order to extract data from a targeted population of emergency HCWs and thus answer our research questions. Continuous monitoring of food intake may be relevant and mandatory in future research. On the other hand, few studies consider the diet of emergency HCWs, and when this is the case, it concerns nurses [55]. Our study is therefore the first to look at the nutrition of emergency physicians during night shifts. Unfortunately, we did not study the food intake the day following the night shift. We previously showed that a night shift has a prolonged effect on some outcomes such as biomarkers of stress [23,24]. Further studies assessing the food intake during rest after a night shift could be relevant. Finally, very few studies have looked at the impact of night work on emergency physicians [24]. It would, therefore, be interesting to conduct more prospective and interventional studies to try to explore all the underlying mechanisms and subsequently put in place health-promotion and/or preventive strategies.

\section{Conclusions}

We showed that emergency healthcare workers working during nightshift have a lower amount and quality of nutrient intake. They seem to eat less and less healthily. Furthermore, sometimes some emergency HCWs go for long hours without eating. One fifth of them do not even drink for more than 8 consecutive hours of night shifts. Further studies assessing the food intake during rest after night shifts could be relevant. Preventive policies should target those workers.

Author Contributions: Conceptualization, J.-B.B.-M. and F.D.; methodology, J.-B.B.-M., J.S., G.B., and F.D.; formal analysis, S.C.; investigation, J.-B.B.-M., F.D. and J.S.; data curation, F.D.; writing-original draft preparation, J.-B.B.-M.; writing-review and editing, D.T., É.A., O.J.A., U.C.U., R.B., G.T.V. and M.T.; visualization, C.C. All authors have read and agreed to the published version of the manuscript.

Funding: This research received no external funding.

Institutional Review Board Statement: The study was conducted in accordance with the Declaration of Helsinki, and approved by the Ethics Committee South-East I of France, for studies involving humans.

Informed Consent Statement: Informed consent was obtained from all subjects involved in the study.

Data Availability Statement: All relevant data are in this manuscript.

Acknowledgments: To all emergency health care workers that were involved in this manuscript.

Conflicts of Interest: The authors declare no conflict of interest. 


\section{Appendix A}
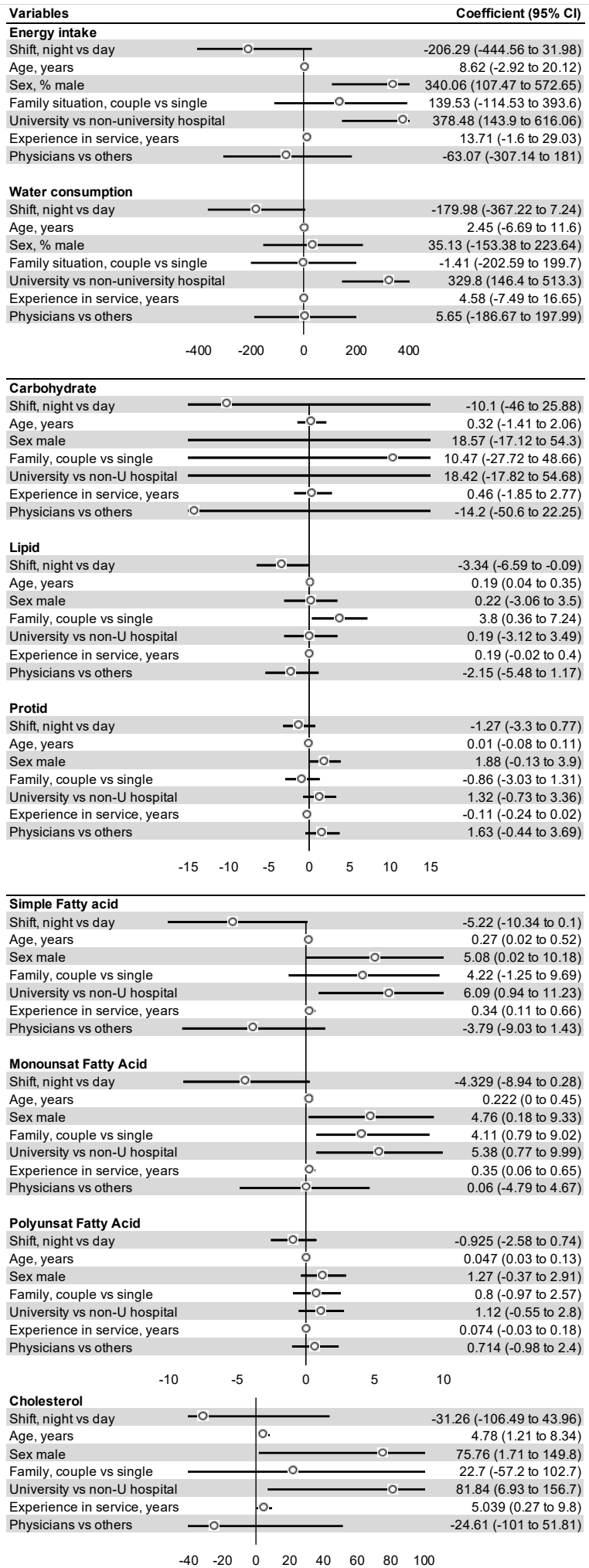

Figure A1. Univariate analysis that found a strong tendency on the impact of night shift on energy intake, water consumption, carbohydrate, lipid, protids, simple fatty acid, monounsaturated fatty acid, polyunsaturated fatty acid and cholesterol. Coefficient up to 0 induces a positive impact of the variable (right side of the reference line). Negative coefficient induces a negative impact of the variable (left side of the reference line); $95 \%$ CI: 95\% confidence interval. Other significant results are described in the results part. 


\section{References}

1. Convention C171-Night Work Convention, 1990 (No. 171). Available online: https://www.ilo.org/dyn/normlex/en/f?p= NORMLEXPUB:12100:0::NO::P12100_INSTRUMENT_ID:312316 (accessed on 4 November 2021).

2. Hansen, J. Night Shift Work and Risk of Breast Cancer. Curr. Environ. Health Rep. 2017, 4, 325-339. [CrossRef] [PubMed]

3. Rajaratnam, S.M.; Arendt, J. Health in a 24-h Society. Lancet 2001, 358, 999-1005. [CrossRef]

4. Boivin, D.B.; Boudreau, P. Impacts of Shift Work on Sleep and Circadian Rhythms. Pathol. Biol. 2014, 62, 292-301. [CrossRef] [PubMed]

5. $\quad$ Ganesan, S.; Magee, M.; Stone, J.E.; Mulhall, M.D.; Collins, A.; Howard, M.E.; Lockley, S.W.; Rajaratnam, S.M.W.; Sletten, T.L. The Impact of Shift Work on Sleep, Alertness and Performance in Healthcare Workers. Sci. Rep. 2019, 9, 4635. [CrossRef]

6. Kosmadopoulos, A.; Kervezee, L.; Boudreau, P.; Gonzales-Aste, F.; Vujovic, N.; Scheer, F.A.J.L.; Boivin, D.B. Effects of Shift Work on the Eating Behavior of Police Officers on Patrol. Nutrients 2020, 12, 999. [CrossRef]

7. Lim, Y.C.; Hoe, V.C.W.; Darus, A.; Bhoo-Pathy, N. Association between Night-Shift Work, Sleep Quality and Metabolic Syndrome. Occup. Environ. Med. 2018, 75, 716-723. [CrossRef]

8. Vetter, C.; Devore, E.E.; Wegrzyn, L.R.; Massa, J.; Speizer, F.E.; Kawachi, I.; Rosner, B.; Stampfer, M.J.; Schernhammer, E.S Association Between Rotating Night Shift Work and Risk of Coronary Heart Disease Among Women. JAMA 2016, 315, 1726-1734. [CrossRef]

9. Dutheil, F.; Baker, J.S.; Mermillod, M.; De Cesare, M.; Vidal, A.; Moustafa, F.; Pereira, B.; Navel, V. Shift Work, and Particularly Permanent Night Shifts, Promote Dyslipidaemia: A Systematic Review and Meta-Analysis. Atherosclerosis 2020, 313, 156-169. [CrossRef]

10. Sun, M.; Feng, W.; Wang, F.; Li, P.; Li, Z.; Li, M.; Tse, G.; Vlaanderen, J.; Vermeulen, R.; Tse, L.A. Meta-Analysis on Shift Work and Risks of Specific Obesity Types. Obes. Rev. Off. J. Int. Assoc. Study Obes. 2018, 19, 28-40. [CrossRef]

11. Keski-Rahkonen, A.; Mustelin, L. Epidemiology of Eating Disorders in Europe: Prevalence, Incidence, Comorbidity, Course, Consequences, and Risk Factors. Curr. Opin. Psychiatry 2016, 29, 340-345. [CrossRef]

12. Samhat, Z.; Attieh, R.; Sacre, Y. Relationship between Night Shift Work, Eating Habits and BMI among Nurses in Lebanon. BMC Nurs. 2020, 19, 25. [CrossRef]

13. Palla, L.; Almoosawi, S. Diurnal Patterns of Energy Intake Derived via Principal Component Analysis and Their Relationship with Adiposity Measures in Adolescents: Results from the National Diet and Nutrition Survey RP (2008-2012). Nutrients 2019, 11, 422. [CrossRef] [PubMed]

14. Bonham, M.P.; Kaias, E.; Zimberg, I.; Leung, G.K.W.; Davis, R.; Sletten, T.L.; Windsor-Aubrey, H.; Huggins, C.E. Effect of Night Time Eating on Postprandial Triglyceride Metabolism in Healthy Adults: A Systematic Literature Review. J. Biol. Rhythm. 2019, 34, 119-130. [CrossRef] [PubMed]

15. Gupta, C.C.; Centofanti, S.; Dorrian, J.; Coates, A.; Stepien, J.M.; Kennaway, D.; Wittert, G.; Heilbronn, L.; Catcheside, P.; Noakes, M.; et al. Altering Meal Timing to Improve Cognitive Performance during Simulated Nightshifts. Chronobiol. Int. 2019, 36, 1691-1713. [CrossRef] [PubMed]

16. Abdella, H.M.; Farssi, H.O.E.; Broom, D.R.; Hadden, D.A.; Dalton, C.F. Eating Behaviours and Food Cravings; Influence of Age, Sex, BMI and FTO Genotype. Nutrients 2019, 11, 377. [CrossRef]

17. Padilla, H.M.; Wilson, M.; Vandenberg, R.J.; Davis, M.; Clark, M.A. Health Behavior among Working Adults: Workload and Exhaustion Are Associated with Nutrition and Physical Activity Behaviors That Lead to Weight Gain. J. Health Psychol. 2021, 26, 892-904. [CrossRef]

18. Nishitani, N.; Sakakibara, H.; Akiyama, I. Eating Behavior Related to Obesity and Job Stress in Male Japanese Workers. Nutrition 2009, 25, 45-50. [CrossRef] [PubMed]

19. Pepłońska, B.; Nowak, P.; Trafalska, E. The Association between Night Shift Work and Nutrition Patterns among Nurses: A Literature Review. Med. Pract. 2019, 70, 363-376. [CrossRef]

20. Bouillon-Minois, J.-B.; Trousselard, M.; Pereira, B.; Schmidt, J.; Clinchamps, M.; Thivel, D.; Ugbolue, U.C.; Moustafa, F.; Occelli, C.; Vallet, G.; et al. Protocol of the Study on Emergency Health Care Workers' Responses Evaluated by Karasek Questionnaire: The SEEK-Study Protocol. Int. J. Environ. Res. Public Health 2021, 18, 4068. [CrossRef]

21. Durand, A.-C.; Bompard, C.; Sportiello, J.; Michelet, P.; Gentile, S. Stress and Burnout among Professionals Working in the Emergency Department in a French University Hospital: Prevalence and Associated Factors. Work Read. Mass 2019, 63, 57-67. [CrossRef]

22. Bouillon-Minois, J.-B.; Roux, V.; Pereira, B.; Flannery, M.; Pelissier, C.; Occelli, C.; Schmidt, J.; Navel, V.; Dutheil, F. Stress among Emergency Health Care Workers on Nuclear or Radiation Disaster: A Preliminary State Survey. Int. J. Environ. Res. Public Health 2021, 18, 8384. [CrossRef] [PubMed]

23. Dutheil, F.; Trousselard, M.; Perrier, C.; Lac, G.; Chamoux, A.; Duclos, M.; Naughton, G.; Mnatzaganian, G.; Schmidt, J. Urinary Interleukin-8 Is a Biomarker of Stress in Emergency Physicians, Especially with Advancing Age-The JOBSTRESS* Randomized Trial. PLoS ONE 2013, 8, e71658. [CrossRef] [PubMed]

24. Dutheil, F.; Boudet, G.; Perrier, C.; Lac, G.; Ouchchane, L.; Chamoux, A.; Duclos, M.; Schmidt, J. JOBSTRESS Study: Comparison of Heart Rate Variability in Emergency Physicians Working a 24-Hour Shift or a 14-Hour Night Shift—A Randomized Trial. Int. J. Cardiol. 2012, 158, 322-325. [CrossRef] [PubMed] 
25. O'Neill, M.; Mujahid, M.; Hutson, M.; Fukutome, A.; Robichaud, R.; Lopez, J. Investing in Public School Kitchens and Equipment as a Pathway to Healthy Eating and Equitable Access to Healthy Food. J. Sch. Health 2020, 90, 492-503. [CrossRef]

26. Tremblay, A.; Clinchamps, M.; Pereira, B.; Courteix, D.; Lesourd, B.; Chapier, R.; Obert, P.; Vinet, A.; Walther, G.; Chaplais, E.; et al Dietary Fibres and the Management of Obesity and Metabolic Syndrome: The RESOLVE Study. Nutrients 2020, $12,2911$. [CrossRef]

27. Nutrient Recommendations: Dietary Reference Intakes (DRI). Available online: https:/ / ods.od.nih.gov/HealthInformation/ Dietary_Reference_Intakes.aspx (accessed on 19 November 2021).

28. Reeves, S.L.; Newling-Ward, E.; Gissane, C. The Effect of Shift-work on Food Intake and Eating Habits. Nutr. Food Sci. 2004, 34, 216-221. [CrossRef]

29. Sahu, S.; Dey, M. Changes in Food Intake Pattern of Nurses Working in Rapidly Rotating Shift. Al Ameen J. Med. Sci. $2011,4,9$.

30. Naghashpour, M.; Amani, R.; Nematpour, S.; Haghighizadeh, M.H. Dietary, Anthropometric, Biochemical and Psychiatric Indices in Shift Work Nurses. Food Nutr. Sci. 2013, 4, 1239-1246. [CrossRef]

31. Tada, Y.; Kawano, Y.; Maeda, I.; Yoshizaki, T.; Sunami, A.; Yokoyama, Y.; Matsumoto, H.; Hida, A.; Komatsu, T.; Togo, F. Association of Body Mass Index with Lifestyle and Rotating Shift Work in Japanese Female Nurses. Obesity 2014, 22, $2489-2493$. [CrossRef]

32. Beebe, D.; Chang, J.J.; Kress, K.; Mattfeldt-Beman, M. Diet Quality and Sleep Quality among Day and Night Shift Nurses. J. Nurs. Manag. 2017, 25, 549-557. [CrossRef]

33. Ramin, C.; Devore, E.E.; Wang, W.; Pierre-Paul, J.; Wegrzyn, L.R.; Schernhammer, E.S. Night Shift Work at Specific Age Ranges and Chronic Disease Risk Factors. Occup. Environ. Med. 2015, 72, 100-107. [CrossRef] [PubMed]

34. Xu, H.G.; Johnston, A.N.B.; Greenslade, J.H.; Wallis, M.; Elder, E.; Abraham, L.; Thom, O.; Carlström, E.; Crilly, J. Stressors and Coping Strategies of Emergency Department Nurses and Doctors: A Cross-Sectional Study. Australas. Emerg. Care 2019, 22, 180-186. [CrossRef] [PubMed]

35. Bouillon-Minois, J.-B.; Schmidt, J.; Dutheil, F. SARS-CoV-2 Pandemic and Emergency Medicine: The Worst Is yet to Come. Am. J. Emerg. Med. 2020, 42, 246-247. [CrossRef] [PubMed]

36. Bouillon-Minois, J.-B.; Raconnat, J.; Clinchamps, M.; Schmidt, J.; Dutheil, F. Emergency Department and Overcrowding During COVID-19 Outbreak; a Letter to Editor. Arch. Acad. Emerg. Med. 2021, 9, e28. [CrossRef]

37. Bremner, J.D.; Moazzami, K.; Wittbrodt, M.T.; Nye, J.A.; Lima, B.B.; Gillespie, C.F.; Rapaport, M.H.; Pearce, B.D.; Shah, A.J.; Vaccarino, V. Diet, Stress and Mental Health. Nutrients 2020, 12, 2428. [CrossRef] [PubMed]

38. Bouillon-Minois, J.-B.; Trousselard, M.; Thivel, D.; Gordon, B.A.; Schmidt, J.; Moustafa, F.; Oris, C.; Dutheil, F. Ghrelin as a Biomarker of Stress: A Systematic Review and Meta-Analysis. Nutrients 2021, 13, 784. [CrossRef]

39. Bouillon-Minois, J.-B.; Trousselard, M.; Thivel, D.; Benson, A.C.; Schmidt, J.; Moustafa, F.; Bouvier, D.; Dutheil, F. Leptin as a Biomarker of Stress: A Systematic Review and Meta-Analysis. Nutrients 2021, 13, 3350. [CrossRef]

40. Dutheil, F.; de Saint Vincent, S.; Pereira, B.; Schmidt, J.; Moustafa, F.; Charkhabi, M.; Bouillon-Minois, J.-B.; Clinchamps, M. DHEA as a Biomarker of Stress: A Systematic Review and Meta-Analysis. Front. Psychiatry 2021, 12, 688367. [CrossRef]

41. St-Onge, M.-P.; Pizinger, T.; Kovtun, K.; RoyChoudhury, A. Sleep and Meal Timing Influence Food Intake and Its Hormonal Regulation in Healthy Adults with Overweight/Obesity. Eur. J. Clin. Nutr. 2019, 72, 76-82. [CrossRef]

42. Geliebter, A.; Gluck, M.E.; Tanowitz, M.; Aronoff, N.J.; Zammit, G.K. Work-Shift Period and Weight Change. Nutrition 2000, 16, 27-29. [CrossRef]

43. Roskoden, F.C.; Krüger, J.; Vogt, L.J.; Gärtner, S.; Hannich, H.J.; Steveling, A.; Lerch, M.M.; Aghdassi, A.A. Physical Activity, Energy Expenditure, Nutritional Habits, Quality of Sleep and Stress Levels in Shift-Working Health Care Personnel. PLoS ONE 2017, 12, e0169983. [CrossRef]

44. Han, K.; Choi-Kwon, S.; Kim, K.S. Poor Dietary Behaviors among Hospital Nurses in Seoul, South Korea. Appl. Nurs. Res. ANR 2016, 30, 38-44. [CrossRef] [PubMed]

45. Almajwal, A.M. Stress, Shift Duty, and Eating Behavior among Nurses in Central Saudi Arabia. Saudi Med. J. 2016, 37, 191-198. [CrossRef] [PubMed]

46. Elizabeth, L.; Machado, P.; Zinöcker, M.; Baker, P.; Lawrence, M. Ultra-Processed Foods and Health Outcomes: A Narrative Review. Nutrients 2020, 12, 1955. [CrossRef]

47. Jia, P.; Luo, M.; Li, Y.; Zheng, J.-S.; Xiao, Q.; Luo, J. Fast-Food Restaurant, Unhealthy Eating, and Childhood Obesity: A Systematic Review and Meta-Analysis. Obes. Rev. Off. J. Int. Assoc. Study Obes. 2021, 22 (Suppl. 1), e12944. [CrossRef] [PubMed]

48. Heath, G.; Dorrian, J.; Coates, A. Associations between Shift Type, Sleep, Mood, and Diet in a Group of Shift Working Nurses. Scand. J. Work. Environ. Health 2019, 45, 402-412. [CrossRef]

49. Bilski, B. Influence of shift work on the diet and gastrointestinal complains among nurses. A pilot study. Med. Pract. 2006, $57,15-19$.

50. Morikawa, Y.; Miura, K.; Sasaki, S.; Yoshita, K.; Yoneyama, S.; Sakurai, M.; Ishizaki, M.; Kido, T.; Naruse, Y.; Suwazono, Y.; et al. Evaluation of the Effects of Shift Work on Nutrient Intake: A Cross-Sectional Study. J. Occup. Health 2008, 50, 270-278. [CrossRef]

51. Dietary Behavior and Its Relation with Lifestyle, Rotating Work Shifts and Job Satisfaction among Nurses of Ain Shams University Hospitals. Egypt. J. Community Med. 2016, 34, 75-86. [CrossRef]

52. Grzymisławska, M.; Puch, E.A.; Zawada, A.; Grzymisławski, M. Do Nutritional Behaviors Depend on Biological Sex and Cultural Gender? Adv. Clin. Exp. Med. 2020, 29, 165-172. [CrossRef] 
53. Dutheil, F.; Chaplais, E.; Vilmant, A.; Courteix, D.; Duche, P.; Abergel, A.; Pfabigan, D.M.; Han, S.; Mobdillon, L.; Vallet, G.T.; et al. Stress Management in Obesity during a Thermal Spa Residential Programme (ObesiStress): Protocol for a Randomised Controlled Trial Study. BMJ Open 2019, 9, e027058. [CrossRef] [PubMed]

54. Santa Cecília Silva, A.A.; Lopes, T.D.V.C.; Teixeira, K.R.; Mendes, J.A.; de Souza Borba, M.E.; Mota, M.C.; Waterhouse, J.; Crispim, C.A. The Association between Anxiety, Hunger, the Enjoyment of Eating Foods and the Satiety after Food Intake in Individuals Working a Night Shift Compared with after Taking a Nocturnal Sleep: A Prospective and Observational Study. Appetite 2017, 108, 255-262. [CrossRef] [PubMed]

55. Nicholls, R.; Perry, L.; Duffield, C.; Gallagher, R.; Pierce, H. Barriers and Facilitators to Healthy Eating for Nurses in the Workplace: An Integrative Review. J. Adv. Nurs. 2017, 73, 1051-1065. [CrossRef] [PubMed] 